\title{
Variable returns to scale DEA-Taguchi approach for ternary additives optimization in expansive soil subgrade enhancement
}

\author{
Chijioke Christopher Ikeagwuani* (i) and Donald Chimobi Nwonu* (1)
}

\author{
${ }^{*}$ Correspondence: \\ chijioke.ikeagwuani@unn. \\ edu.ng; donald.Nwonu@unn. \\ edu.ng \\ Civil Engineering \\ Department, University \\ of Nigeria, Nsukka, Enugu \\ State, Nigeria
}

\begin{abstract}
In this study, variable returns to scale (VRS) data envelopment analysis was integrated into the Taguchi approach to optimize ternary additives for expansive soil enhancement. The ternary additives selected were sawdust ash (SDA), quarry dust (QD) and ordinary Portland cement (OPC). The additives were set as the input variables while multiple responses obtained from the experiments performed with the Taguchi orthogonal array were set as the output variables. Each row in the orthogonal array were defined as a decision making unit (DMU) in the optimization process and output-oriented VRS model was used to obtain the efficiency score for each DMU. Next, benevolent formulation was utilized to obtain the multipliers for the inputs and outputs which were subsequently used to determine the cross efficiency scores for each DMU. The cross-efficiency scores were used to construct the cross-efficiency matrix. Thereafter, the mean cross-efficiency score (MCES) was determined for each DMU. Parameter level that maximizes the MCES was chosen as the optimal level for that parameter. Optimum combination of additives was found at A6 B2 C3. Lastly, confirmatory experiments performed by blending the soil with the optimum combination of additives showed the effectiveness of this method in the enhancement of expansive soil properties.
\end{abstract}

Keywords: Additives, Expansive soil, Data envelopment analysis, Optimization, Taguchi method, Variable returns to scale

\section{Introduction}

During construction of geotechnical and highway structures, a common setback often encountered in practice is the unsuitability of some natural materials such as expansive soil found in situ. Expansive soil is known to be widely distributed predominantly in parched regions [1-3]. It is associated with significant volume change due to its susceptibility to moisture variability. It has the propensity to swell and shrink depending on the prevailing moisture condition. Infrastructures constructed on it portend great georisk to the surrounding due to stability concerns of the infrastructures. Several palliative measures are usually sought after during construction to mitigate the dangers posed by the soil [4-11]. The commonly used palliative measure is the replacement strategy in which

(c) The Author(s) 2021. This article is licensed under a Creative Commons Attribution 4.0 International License, which permits use, sharing adaptation, distribution and reproduction in any medium or format, as long as you give appropriate credit to the original author(s) and the source, provide a link to the Creative Commons licence, and indicate if changes were made. The images or other third party material in this article are included in the article's Creative Commons licence, unless indicated otherwise in a credit line to the material. If material is not included in the article's Creative Commons licence and your intended use is not permitted by statutory regulation or exceeds the permitted use, you will need to obtain permission directly from the copyright holder. To view a copy of this licence, visit http://creativeco mmons.org/licenses/by/4.0/. 
the soil is expected to be replaced with suitable geomaterials. This measure is ideal when the soil strata is only surficial. However, in cases where the soil extends to considerable depth below the ground surface, soil stabilization technique, which is an economical palliative measure, is usually adopted.

Soil stabilization involves blending soil with suitable geomaterials under appropriate conditions to obtain a composite mixture with enhanced soil properties. Different soil stabilization schemes are frequently executed in practice but the ones to be applied on a particular site are usually decided principally by the highway or geotechnical engineer [2]. In addition, the geomaterials used for soil stabilization by engineers are selected based on their reported performance in several studies conducted by different researchers. The geomaterials are categorized into traditional and non-traditional additives. Some of the traditional additives include cement, lime, fly ash, et cetera while the nontraditional ones include cement kiln dust (CKD), sawdust ash (SDA), mine tailings, coal bottom ash, bagasse ash, sulphonated oil and others [12-15].

The use of traditional additives such as lime and cement has been reported to be efficient in the enhancement of the properties of expansive soils. However, a notable concern with their continuous usage is the environmental challenges associated with them. These environmental challenges include the increase in $\mathrm{pH}$ of the soil and carbon footprint which is not unconnected with their production. Adverse effect of the undue increase in the $\mathrm{pH}$ of the soil when treated with the traditional additives is rife in literature [16-19]. As a consequence, there has been a paradigm shift towards the utilization of additives which possesses little or no environmental challenge for expansive soil stabilization. Most recent studies utilize a combination of the traditional and non-traditional additives to limit the environmental challenges caused by the sole usage of the traditional additives.

In a study by Ikeagwuani et al. [1], a combination of lime and SDA were used to treat black cotton soil, which is an expansive soil. The result obtained show that the best performance was achieved when a combination of $4 \%$ lime and 16\% SDA were added to the soil. Similarly, rice husk ash and calcium carbide residue were combined by Liu et al. [20] to treat an expansive soil and an improved performance of the soil was reported when the additives were added to it. In a related study conducted by Phanikumar and Raju [21] on the improvement of an expansive soil, cement and lime sludge were mixed together to treat the soil and it was discovered that the pozzolanic reaction that occurred between the two additives and the soil resulted in the improved performance observed in the soil. The improved performance became apparent when 10\% cement and 12\% lime sludge content were blended with the expansive soil. In a similar development, a combination of hydrated lime and lignosulphate was used by Ijaz et al. [22] to stabilize an expansive soil and it was reported that an optimal combination of $2.625 \%$ hydrated lime and $0.875 \%$ lignosulphate content yielded the desired improvement in the soil properties.

Despite the degree of successes recorded in the combination and usage of the traditional and non-traditional additives in expansive soil stabilization, the current mode of stabilization can best be described as trial and error method, which is neither cost nor time effective. Fortunately, optimization schemes can provide improved and robust approaches when integrated in the stabilization process [8]. However, their integration in soil stabilization techniques has only been reported in very few literatures to the 
extent of the knowledge of the authors. The use of response surface methodology (RSM) has claimed some level of successes in expansive soil stabilization [23, 24]. Interestingly, other optimization schemes which exist in literature and are capable of optimizing additives for expansive soil stabilization can also be explored. One of such optimization schemes, which has proven to be robust in product development, is the Taguchi optimization method.

\section{Taguchi optimization method}

Taguchi optimization technique, which is a widely adopted analytical tool for quality product design, was developed by a Japanese quality control expert, Genichi Taguchi [25]. The method bears a unique advantage as it significantly reduces the number of experiments required for robust product development. This unique advantage makes it preferable to other methods of experimental design including the RSM and other classical design of experiment (DOE) methods. Taguchi method provides a systematic approach in the variation of process parameter levels to attain the target response value [26] unlike other DOE methods that are usually executed using either full or fractional factorial test designs. The full or fractional test designs have inherent shortcomings such as time and cost-intensive nature (in the case of full factorial designs) and the use of undefined rules which makes the method more or less a trial and error method (in the case of fractional factorial designs) [27-29].

Taguchi surmounted the shortcomings of the classical DOE methods by adopting the use of orthogonal array for experimental designs. The orthogonal array is an approach with a mathematical framework developed by Hadamard, a French mathematician [30]. It reduces the number of designed experiments to the barest minimum but still achieves a balanced design. This is because every possible combination of the process parameters is utilized for any two consecutive columns to produce a mutually orthogonal array [26]. The key quality control tool employed by the Taguchi optimization technique is the signal-to-noise $(\mathrm{S} / \mathrm{N})$ ratio, which ensures that the desired outcome for each quality characteristic is optimally targeted [30]. The combined utilization of orthogonal array and $\mathrm{S} / \mathrm{N}$ ratio by the Taguchi optimization method makes it a robust approach and the preferred optimization technique in several fields. Using the vacuum membrane distillation method, phenolic wastewater was efficiently treated by optimization of the process parameters through the Taguchi method [31], which shows a successful application in wastewater engineering. The method was also applied in the field of environmental science for effective pesticide removal using zeolite modified soil [32]. Several other applications exist in literature [33-38].

Despite the level of successes recorded with the utilization of the Taguchi optimization method, it still exhibits the inherent limitation of single response optimization associated with every other DOE method. In order to circumvent this drawback when confronted with multiple response problems, the Taguchi method is usually integrated into some numerical and analytical techniques to achieve multiple response optimization [39-46]. However, most of the developed numerical and analytical techniques for Taguchi multiple response optimization present modest results due to their inherent shortcomings [47], which poses a huge setback to the wide acceptance of the Taguchi optimization method. As such, the need for more thorough approaches toward solving 
the multiple response optimization becomes crucial. The present study explored the use of a thorough numerical technique known as variable returns to scale data envelopment analysis model for Taguchi multiple response optimization; involving expansive soil stabilization process.

\section{Data envelopment analysis}

Data envelopment analysis (DEA) is a nonparametric mathematical linear programming technique used for the assessment of relative efficiencies of an array of decision-making units (DMUs) that comprises multiple inputs and multiple outputs. It was developed by Charnes et al. [48] for the assessment of efficient (best practice) frontier and to distinguish efficient units from the inefficient ones based on the recorded input and output values. The DEA is a body of methodologies and concepts that have been integrated into a group of models that has different interpretive possibilities [49]. They include the constant returns to scale (CRS) model which is also known as the Charnes, Cooper and Rhodes (CCR) model; the Bankers, Cooper and Rhodes (BCC) model; the multiplicative models; the additive models and the slack based measure (SBM) models. The most common among these models are the CCR and the BCC models which are often referred to as the classical DEA models because they were the earliest forms of the DEA models.

The DEA models are broadly divided into two groups based on their orientation. They are the input-oriented models and the output-oriented models. In the input-oriented models, the DMU under evaluation can have a proportional reduction in its input level as it advances towards the efficient frontiers whilst retaining its outputs at their existing levels. In the output-oriented models, the DMU under evaluation can have a proportional increase in its output whilst retaining its inputs at their existing levels. The striking feature of the DEA is its flexibility in multiplier selection during the estimation of the efficiency of a DMU. During efficiency estimation, each DMU is allowed to choose multipliers (weights) for its multiple inputs and outputs that is highly favorable to it. The efficiency so obtained is the greatest efficiency the DMU can achieve. This feature made the DEA to be accepted globally in the measurement of efficiencies.

However, the problem with this flexibility feature is the inability to discriminate among efficient DMUs because several DMUs may lie at the efficient frontier. With more than one DMU lying at the efficient frontier, comparison among their efficiencies become a herculean task. Notably, comparison of the efficiencies of DMUs can only be adjudged to be fair if their efficiencies are calculated with similar set of weights. To put a stop to this problem, the concept of cross-efficiency evaluation, which was developed by Sexton et al. [50] and later expanded by Doyle \& Green [51], was introduced as an extension to the DEA technique. This cross-efficiency concept discourages the idea of DMUs being self-evaluated only and encourages peer-evaluation in conjunction with the selfevaluation amongst the DMUs. The objective of the cross-efficiency concept is to utilize the set of weights chosen by the self-evaluated DMUs as a unique set of common weights for the estimation of the efficiencies of other DMUs. Thus, unrealistic weights obtained from the self-evaluated DMUs are obliterated when cross-efficiency evaluation is performed [52]. In addition, discrimination amongst the efficient DMUs is also vastly improved. 
Notwithstanding the benefit of the cross-efficiency evaluation in the DEA, the problem of non-uniqueness of the optimal solutions in the classical DEA often limits its usage. To overcome this challenge, a secondary goal is usually incorporated into the traditional DEA. Several scholars have developed different secondary goals for the classical DEA models. Some of the secondary goals are the well established aggressive and benevolent formulation [51], neutral DEA concept [53], maxmin formulation [54] and the symmetric weight assignment approach [55]. Other secondary goals include the coordinate translation method [56], integration of SBM model in the DEA [57], target identification model [58] and the game cross-efficiency model which represents a Nash equilibrium point [59]. Some other scholars who have also contributed to the secondary goals include Liu [60], Ramon et al. [61] and Yang et al. [62].

Interestingly, the introduction of secondary goals to the DEA has led to its widespread utilization in various disciplines. Wu et al. [63] successfully utilized the concept of the cross efficiency evaluation for the measurement of performance of countries that participated in the summer Olympic from 1984 to 2004. Wu et al. [64] effectively employed cross-efficiency evaluation concept to assess the performance of different container ports situated in 12 different countries. Lim et al. [65] applied DEA cross-efficiency concept to choose stock portfolio in the Stock market of Korea. Gavgani \& Zohrehbandia [66] used the concept of cross-efficiency for the assessment of performance of staff working in six nursing homes. Sun et al. [67] evaluated the efficiency of infrastructure investment of various capital cities in China using the cross-efficiency evaluation.

There are other numerous applications of the cross-efficiency concept in literature. However, it is highly necessary to note that cross efficiency concept is often utilized mainly for CRS models. This is largely due to the negative efficiency scores that are generated from the input-oriented BCC models. Negative scores are not reasonable and usually pose serious challenge in the estimation of the final efficiency of DMUs. Interestingly, its counterpart, the output-oriented BCC models, do not produce negative efficiency scores and by extension, reasonable weights are produced from it that can be utilized by practitioners especially geotechnical and highway engineers. Consequently, this study adopted the classical output-oriented BCC model together with the benevolent formulation as a secondary goal for the optimization of additives in the improvement of expansive soil. The BCC model was integrated into the Taguchi method in the optimization process.

\section{BCC model}

The BCC model, which was proposed by Banker, Cooper and Rhodes [68], is also known as the variable returns to scale (VRS) model. The VRS model is an extension of the CRS model. The difference between both models is that the assumption imposed on the CRS is relaxed in the VRS model. Data involved in the VRS model are much more enveloped than that of the CRS model. This result in the production of technical efficiencies that are equal to or even greater than those of the CRS model. Furthermore, efficiency variation with regards to its scale of operation are accounted for in the VRS model, and this lead to pure technical efficiency being measured in the VRS model [69]. BCC model is described as efficient if its efficiency is equal to unity; otherwise, it is described as inefficient. 
The BCC model can be represented in the envelopment form or in the multiplier form whose orientation can either be input oriented or output oriented. One of these two orientations can be used for benchmarking depending on the goal of the decision maker [70]. However, in this study, the multiplier form of the output-oriented BCC model was utilized for the optimization process. The multiplier form, which was integrated into the Taguchi method for the optimization of additives for expansive soil enhancement, was utilized because it is best suited for geotechnical and highway engineering problems. In addition, it reflects the main objective of the optimization process which is to reduce or keep the inputs at their current level whilst seeking the maximization of the outputs. The equations for the multiplier form of input-oriented BCC model and output-oriented $\mathrm{BCC}$ model used for estimation of a DMU under evaluation $\operatorname{DMU}_{\mathrm{k}}(k \in\{1, \ldots, n\})$. are expressed as shown in Eqs. (1) and (2).

Input-oriented multiplier BCC model

$$
\begin{aligned}
& \text { Maximize } \quad \theta_{k k}=\frac{u_{0 k}+\sum_{r=1}^{s} u_{r k} y_{r k}}{\sum_{i=1}^{m} v_{i k} x_{i k}} \\
& \text { Subject to } \quad \frac{u_{0 k}+\sum_{r=1}^{s} u_{r k} y_{r j}}{\sum_{i=1}^{m} v_{i k} x_{i j}} \leq 1, j=1, \ldots, n, \\
& u_{r k} \geq \varepsilon, r=1, \ldots, s \\
& v_{i k} \geq \varepsilon, i=1, \ldots, m, \\
& u_{0 k} \text { is unconstrained in sign }
\end{aligned}
$$

Equation (1a), which is a fractional program can be expressed in the form of a linear program by using the transformation technique developed by Charnes [71].

$$
\begin{aligned}
& \text { Maximize } \quad \theta_{k k}=u_{0 k}+\sum_{r=1}^{s} u_{r k} y_{r k} \\
& \text { Subject to } \quad \sum_{r=1}^{m} v_{i k} x_{i k}=1, \\
& u_{0 k}+\sum_{r=1}^{s} u_{r k} y_{r j}-\sum_{i=1}^{m} v_{i k} x_{i j} \leq 0, j=1, \ldots, n,
\end{aligned}
$$

$v_{i k} \geq \varepsilon, i=1, \ldots, m$,

$u_{0 k}$ is unconstrained in sign 


\section{Output-oriented multiplier BCC model}

$$
\begin{aligned}
& \text { Minimize } \quad 1 / \theta_{k k}=\frac{v_{0 k}+\sum_{i=1}^{m} v_{i k} x_{i k}}{\sum_{r=1}^{s} u_{r k} y_{r k}} \\
& \text { Subject to } \quad \frac{V_{0 k}+\sum_{i=1}^{m} v_{i k} x_{i j}}{\sum_{i=1}^{s} u_{r k} y_{r j}} \geq 1, j=1, \ldots, n, \\
& \qquad \begin{array}{l}
u_{r k} \geq \varepsilon, r=1, \ldots, s, \\
v_{i k} \geq \varepsilon, i=1, \ldots, m, \\
v_{0 k} \text { is unconstrained in sign }
\end{array}
\end{aligned}
$$

Equation (2a) which is also a fractional program can be expressed as a linear program by using the transformation technique developed by Charnes [71].

$$
\begin{aligned}
& \text { Minimize } \quad 1 / \theta_{k k}=v_{0 k}+\sum_{i=1}^{m} v_{i k} x_{i k} \\
& \text { Subject to } \quad \sum_{r=1}^{s} u_{r k} y_{r k}=1, \\
& \qquad v_{0 k}+\sum_{i=1}^{m} v_{i k} x_{i j}-\sum_{r=1}^{s} u_{r k} y_{r j} \geq 0, j=1, \ldots, n, \\
& u_{r k} \geq \varepsilon, r=1, \ldots, s, \\
& v_{i k} \geq \varepsilon, i=1, \ldots, m,
\end{aligned}
$$

$v_{0 k}$ is unconstrained in sign

where,

$x_{i j}$ denotes the input of each of the $j$ th $\mathrm{DMU}\left(D M U_{j}\right)$

$y_{r j}$ denote the output of each of the $j t h$ DMU.

$n$ represents the number of DMUs to be evaluated.

$m$ represents the number of inputs used by each $D M U_{j}$

$s$ signifies the number of outputs produced by each $D M U_{j}$

$\varepsilon$ represents non-Archimedean infinitesimal.

$v_{i k}$ signifies the input multiplier selected by $\mathrm{DMU}_{\mathrm{k}}$

$u_{r k}$ signifies the output multiplier selected by $\mathrm{DMU}_{\mathrm{k}}$

$\theta_{k k}$ denotes the optimal efficiency of $\mathrm{DMU}_{\mathrm{k}}$

\section{Methodology}

\section{Materials used}

The data used for analysis in this study was extracted from the study that was performed by Ikeagwuani [72]. Ikeagwuani [72] optimized ternary additives for the enhancement of expansive soil properties using the Taguchi method. The expansive soil, sawdust dust (SDA), quarry dust (QD) and ordinary Portland cement (OPC) were the additives used for the optimization. 


\section{Expansive soil}

The expansive soil sample (Fig. 1) used for the investigation in the study conducted by Ikeagwuani [72] was collected from a borrow pit in Numan $\left(9^{\circ} 29^{\prime} 10^{\prime \prime} \mathrm{LN}\right.$, $12^{\circ} 02^{\prime} 36^{\prime \prime}$ LE), Adamawa State, Nigeria. Shortly after collection, the soil sample was pulverized with the aid of a pestle. Ikeagwuani [72] reported that the pulverization was done because the expansive soil was found to be in dried and firm condition when it was collected. The basic soil tests conducted on the natural expansive soil showed that the soil comprises $95.8 \%$ fine particles and $4.2 \%$ sand particles as shown in Table 1. The compaction charcterisitics of the expansive soil which include the optimum moisture content (OMC) and maximum dry density (MDD) were recorded as $23.4 \%$ and $1.55 \mathrm{~g} / \mathrm{cm}^{3}$ respectively. The compaction characteritisitcs were determined using the standard proctor mould. Atterberg limits performed on the soil using the procedure that was stated in BS 1377 (1990) Part 2 showed that the soil has a plastic limit of $23.6 \%$ and a high plasticity index of $43.5 \%$. According to Garg [73] and Holtz \& Gibbs [74] any soil that possesses a plasticity that exceeds $17 \%$ can be regarded as an extremely high plastic soil. The values of the unconfined compressive strength (UCS) and the California bearing ratio (CBR) of the soil as displayed in Table 1 showed that both values did not meet the minimum requirement for design of pavement as laid out in the Nigerian general specification for road and bridges. Furthermore, the soil was classified using the American association of state highway and transportation official [75] and the classification revealed that the soil fell under the A-7-6 group of soil. Chemical composition analysis was conducted on a representative sample of the soil using the X-ray flourescence procedure (ARL-XRF Advant 1200 model) and the result is shown in Table 2 (Fig. 1).

Table 1 Expansive soil properties

\begin{tabular}{|c|c|c|c|}
\hline S/No & Soil property & & Description \\
\hline 1 & Specific gravity & & 2.66 \\
\hline 2 & Fines & & $95.8 \%$ \\
\hline 3 & Sand & & $4.2 \%$ \\
\hline 4 & Natural moisture content & & $8.7 \%$ \\
\hline 5 & Plastic limit & & $23.6 \%$ \\
\hline 6 & Liquid limit & & $67.1 \%$ \\
\hline 7 & Plasticity index & & $43.5 \%$ \\
\hline 8 & Optimum moisture content (OMC) & & $23.4 \%$ \\
\hline 9 & Maximum dry density (BSL) & & $1.546 \mathrm{~g} / \mathrm{cm}^{3}$ \\
\hline 10 & AASHTO classification & & A-7-6 (33) \\
\hline 11 & USCS classification & & $\mathrm{CH}$ \\
\hline 12 & UCS & & $152.482 \mathrm{kN} / \mathrm{m}^{2}$ \\
\hline 13 & DFS & & $71.59 \%$ \\
\hline \multirow[t]{2}{*}{14} & CBR & Unsoaked & $9.4 \%$ \\
\hline & & Soaked & $5.5 \%$ \\
\hline
\end{tabular}


Table 2 Chemical analysis of expansive soil, SDA, QD and OPC

\begin{tabular}{|c|c|c|c|c|}
\hline Element oxide & Soil (\%) & SDA (\%) & QD (\%) & OPC (\%) \\
\hline Silica $\left(\mathrm{SiO}_{2}\right)$ & 58.9 & 41.0 & 71.7 & 12 \\
\hline Iron oxide $\left(\mathrm{Fe}_{2} \mathrm{O}_{3}\right)$ & 23.34 & 6.07 & 4.47 & 4.33 \\
\hline Alumina $\left(\mathrm{Al}_{2} \mathrm{O}_{3}\right)$ & 9.85 & - & 14.7 & - \\
\hline Potash $\left(\mathrm{K}_{2} \mathrm{O}\right)$ & - & 10 & 2.7 & - \\
\hline Lime $(\mathrm{CaO})$ & 1.21 & 38.9 & 3.81 & 80.91 \\
\hline Magnesia (MgO) & - & - & - & - \\
\hline Titanium oxide $\left(\mathrm{TiO}_{2}\right)$ & 3.07 & 0.36 & 1.37 & 0.16 \\
\hline Magnesium oxide (MnO) & 0.03 & 0.42 & - & 0.03 \\
\hline $\mathrm{SO}_{3}$ & - & 0.89 & - & 1.4 \\
\hline $\mathrm{V}_{2} \mathrm{O}_{5}$ & 0.04 & 0.02 & 0.02 & - \\
\hline $\mathrm{Cr}_{2} \mathrm{O}_{3}$ & 0.02 & - & - & - \\
\hline $\mathrm{CuO}$ & 0.06 & 0.06 & 0.04 & 0.02 \\
\hline $\mathrm{ZnO}$ & 0.04 & 0.09 & - & - \\
\hline $\mathrm{Ga}_{2} \mathrm{O}_{3}$ & 0.02 & - & 0.02 & - \\
\hline $\mathrm{Rb}_{2} \mathrm{O}$ & 0.08 & 0.17 & 0.06 & - \\
\hline $\mathrm{SrO}$ & 0.16 & 0.62 & 0.21 & 0.90 \\
\hline $\mathrm{Y}_{2} \mathrm{O}_{3}$ & 0.03 & 0.01 & 0.02 & - \\
\hline $\mathrm{ZrO}_{2}$ & 0.25 & 0.05 & 0.36 & 0.01 \\
\hline $\mathrm{BaO}$ & 0.47 & - & 0.10 & - \\
\hline $\mathrm{Eu}_{2} \mathrm{O}_{3}$ & 0.64 & - & 0.22 & - \\
\hline $\mathrm{Re}_{2} \mathrm{O}_{7}$ & 0.05 & - & - & - \\
\hline $\mathrm{IrO}_{2}$ & 0.07 & - & - & - \\
\hline $\mathrm{ThO}_{2}$ & 0.07 & - & - & - \\
\hline $\mathrm{CO}_{3} \mathrm{O}_{4}$ & - & 0.05 & 0.01 & 0.06 \\
\hline $\mathrm{HgO}$ & - & - & - & 0.03 \\
\hline $\mathrm{PbO}$ & - & - & 0.01 & - \\
\hline $\mathrm{As}_{2} \mathrm{O}_{3}$ & - & - & 0.02 & - \\
\hline Loss on ignition & & & & \\
\hline
\end{tabular}

\section{Quarry dust}

According to Ikeagwuani [72], the quarry dust (QD) used as one of the additives in the optimization process was obtained from Enugu ( $\left.7^{\circ} 32^{\prime} 47^{\prime \prime} \mathrm{LN}, 6^{\circ} 27^{\prime} 31^{\prime \prime} \mathrm{LE}\right)$, Nigeria.

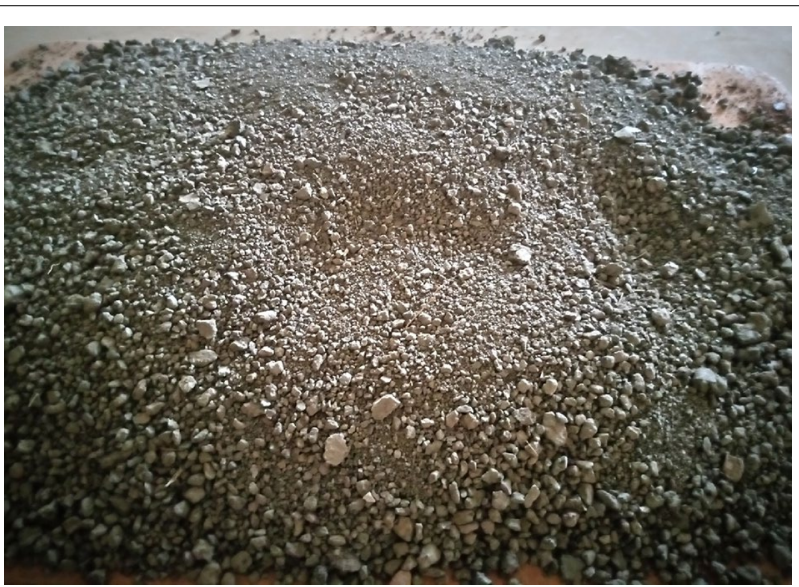

Fig. 1 Sample of the dried natural expansive soil 
QD is an industrial waste product from quarry industries. It is liberated during the crushing of rock [76]. The QD is well known for his environmental pollution when it is discarded inapropriately [77]. Numerous scholars particularly in geotechnical and highway engineering constantly seek to recycle and harness the potential of QD in pavement design [77-81]. The chemical composition analysis of the QD utilized by Ikeagwuani [72] for the optimization process is presented in Table 2. The chemical composition analysis of QD as presented in Table 2 consists of a high percentage of silica.

\section{Sawdust ash}

Sawdust ash (SDA), which was the second additive utilized by Ikeagwuani [72] during the optimization process, was gotten from the residue produced after the incineration of sawdust collected from a dumpsite in Enugu. Ikeagwuani [72] reported that the sawdust was generated using dual-phase production process. The first phase involved the removal of impurities in the sawdust through manual sorting. The removed impurities were discarded and the sawdust was air-dried for a period of $7 \mathrm{~d}$. The second phase involved the incineration stage. In this stage, the air-dried sawdust was gently inserted into a furnace whose heating temperature was set at $800{ }^{\circ} \mathrm{C}$. The sawdust was burnt for $6 \mathrm{~h}$ in the furnace to generate the SDA which was permitted to cool for $24 \mathrm{~h}$ and subsequently made to pass through BS No. 200 test sieve. A representative sample of the cooled SDA was collected from the sieved ones and used for chemical composition analysis. The result of the chemical composition analysis of the SDA as reported by Ikeagwuani [72] is presented in Table 2.

\section{Ordinary Portland cement}

The ordinary Portland cement (OPC) which was the third and last additive utilized by Ikeagwuani [72] was sourced locally. The OPC grade was 32.5R and its chemical composition conforms with the specification stated in the ASTM C150 (ASTM, 2017) code. The oxide composition analysis of the OPC that was utilized by Ikeagwuani [72] is presented in Table 2

\section{Methods}

\section{Laboratory testing procedures}

The experimental procedure stated in BS 1377 [82] was employed by Ikeagwuani [72] for the evaluation of the basic soil properties of the expansive soil. Only the Differential free swell (DFS) test was evaluated with the experimental procedure stated in IS 2720, Part 40 [83]. The basic soil properties of the soil evaluated included compaction, UCS, specific gravity, Atterberg limits, CBR and natural moisture. BS 1377 [82] experimental procedure was also employed by Ikeagwuani [72] to evaluate the UCS and CBR, which were the first two responses considered in his study while the IS 2720, Part 40 [83] was utilized for the evaluation of the last response (DFS).

\section{Compaction}

Compaction test was executed as per BS 1377, Part 4 [84] experimental procedure for the determination of the OMC and MDD of the natural soil. The BS 1377, Part 4 [84] 
experimental procedure was also used to execute the compaction test for the samples that were prepared with the various mix ratios obtained from the mixed level Taguchi orthogonal array. As reported by Ikeagwuani [72], a standard proctor mould whose volume was $0.001 \mathrm{~m}^{3}$ along with a standard rammer whose weight was $2.5 \mathrm{~kg}$ were utilized for the test. The soil samples were poured into the mould in three layers and each layer was compacted by subjecting it to 27 blows with the help of the rammer. The rammer was permitted to fall under its own weight from a height of $300 \mathrm{~mm}$.

\section{CBR test}

The CBR test was performed in accordance with BS 1377, Part 4 [84] experimental procedure. The test was done on soil samples prepared with the various mix ratios obtained from the mixed level Taguchi orthogonal array as well as on the natural expansive soil sample. Both unsoaked and soaked CBR tests were carried out for the natural expansive soil. The soaked CBR test was performed after immersing the natural expansive soil in water for $96 \mathrm{~h}$. For the soil samples prepared with the various mix ratios gotten from the Taguchi orthogonal array, only unsoaked CBR test was performed on them. According to Ikeagwuani [72], the unsoaked CBR test was performed after curing the samples for 7 $\mathrm{d}$ in a humidity-controlled environment. Before performing the CBR test, two surcharge circular disks, whose combined weight was $4.5 \mathrm{~kg}$, were gently placed on the soil samples and the entire assembly were placed onto the CBR machine loading frame. Axial force was applied to the soil samples through a $50 \mathrm{~mm}$ metallic plunger that was permitted to penetrate the soil samples at strain rate of $1.25 \mathrm{~mm} / \mathrm{min}$ until failure occurred. Subsequently, the CBR values of the soil samples were estimated corresponding to settlements at $2.5 \mathrm{~mm}$ and $5 \mathrm{~mm}$.

\section{UCS test}

As reported by Ikeagwuani [72], the UCS test was performed in accordance with the experimental guidelines stated in BS 1377, Part 7. Cylindrical soil samples whose height and diameter are 76 and $38 \mathrm{~mm}$ respectively were used to perform the UCS test. The test was performed on both the natural soil sample and the soil samples prepared with the mix ratios generated from the Taguchi mixed level orthogonal array. The soil samples were compacted in standard moulds with moisture content corresponding to their OMC. Extraction of the soil samples were carried out afterwards. The extracted samples were tightly sealed in polyethylene bags and left to cure for $28 \mathrm{~d}$. After curing, the samples were placed in the loading frame of the UCS machine and then loaded axially at strain rate of $1.2 \mathrm{~mm} / \mathrm{min}$ until it failed or reached $20 \%$ of the strain applied to it.

\section{DFS test}

IS 2720, Part 40 [83] experimental guideline was employed by Ikeagwuani [72] to perform the DFS test. The DFS test is used to determine the degree of expansiveness of soil samples containing expandable clay. It involves determining the volume change of two similar soil samples in which one of the soil sample is immersed in water (polar solvent) and the other sample is immersed in kerosene (non-polar solvent). According to Ikeagwuani [72], the soil samples used for the experiment were oven dried for $24 \mathrm{~h}$ prior to the test. After oven-drying, the soil samples were sieved using BS No. 36 test sieve. To 
conduct the test, about $10 \mathrm{~g}$ of sample was collected from a sieved sample, poured into a transparent graduated cylinder containing water, and stirred thoroughly until it was perfectly mixed with the water. In the same vein, another $10 \mathrm{~g}$ of sample was collected from the sieved soil sample and poured into another transparent graduated cylinder containing kerosene. It was also stirred thoroughly with a stirrer until it was perfectly mixed with the kerosene. Both transparent graduated cylinders were allowed to stand undisturbed for $24 \mathrm{~h}$ and the soil sample degree of expansiveness was evaluated shortly after.

\section{Optimization procedure}

As pointed out earlier, this study utilized the data from the experiment performed by Ikeagwuani [72] on the optimization of ternary additives for the enhancement of the properties of expansive soil. Ikeagwuani [72] used the Taguchi approach to optimize the additives. Taguchi orthogonal mixed level array was selected by Ikegwuani [72] for the design of experiment (DOE). The OPC together with the QD were assigned three levels each while only SDA was assigned six levels in the optimization process performed by Ikeagwuani [72] as depicted in Table 3. In Table 4, the Taguchi mixed level orthogonal array used by Ikeagwuani [72] for his optimization process is shown.

As noted earlier, Taguchi approach is only effective for the optimization of single response. Therefore, in order to optimize the ternary additives concurrently, this study proposed an approach which involves the integration of the output-oriented multiplier BCC model and benevolent formulation (secondary goal) into the Taguchi approach utilized by Ikeagwuani [72]. The following four steps were adopted for the concurrent optimization of the ternary additives.

Step 1: Definition of DMU and estimation of the mean responses.

In this initial step, each row in the Taguchi orthogonal array signifies a $D M U_{j}$. The rows consist of various mix ratios and their corresponding responses. The responses are determined by performing experiments in the laboratory. The total number of experiments in the Taguchi orthogonal array represents the total number of DMUs, $n$. The various mix ratios are set as the input variables while their corresponding responses are set as the output variables. Each additive ratio, in each row of the Taguchi orthogonal array, denotes an input, $x_{i j}$, for each $D M U_{j}$; while each response, in each row of the Taguchi array, denotes an output, $y_{r j}$ for each $D M U_{j}$. After defining the DMUs, the average value of each response are calculated.

Step 2: Evaluation of BCC-efficiency.

Step 2 involves the estimation of the relative BCC-efficiency, $\theta_{k k}$, for each DMU. This is performed by solving Eq. (2b) which is the linear form of the output-oriented BCC model.

Step 3: Estimation of optimal weights and construction of cross-efficiency matrix.

Table 3 Additives with their assigned levels

\begin{tabular}{lllrrrr}
\hline S/N & $\begin{array}{l}\text { Parameter } \\
\text { (additive) }\end{array}$ & \multicolumn{2}{l}{ Parameter level } & & \\
\cline { 3 - 7 } & & $\mathbf{1}$ & $\mathbf{2}$ & $\mathbf{3}$ & $\mathbf{4}$ & $\mathbf{5}$ \\
\hline 1 & SDA & 0 & 4 & 8 & 12 & 16 \\
2 & QD & 0 & 10 & 20 & - & - \\
3 & OPC & 2 & 5 & 8 & - & - \\
\hline
\end{tabular}


Table 4 Layout of Taguchi mixed level orthogonal array

\begin{tabular}{|c|c|c|c|c|c|c|}
\hline \multirow{3}{*}{$\begin{array}{l}\text { Number of } \\
\text { experiment }\end{array}$} & \multicolumn{6}{|c|}{ Parameter values } \\
\hline & \multicolumn{3}{|c|}{ Actual values } & \multicolumn{3}{|c|}{ Coded values } \\
\hline & SDA & QD & OPC & A & B & C \\
\hline 1 & 0 & 0 & 2 & 1 & 1 & 1 \\
\hline 2 & 0 & 10 & 5 & 1 & 2 & 2 \\
\hline 3 & 0 & 20 & 8 & 1 & 3 & 3 \\
\hline 4 & 4 & 0 & 2 & 2 & 1 & 1 \\
\hline 5 & 4 & 10 & 5 & 2 & 2 & 2 \\
\hline 6 & 4 & 20 & 8 & 2 & 3 & 3 \\
\hline 7 & 8 & 0 & 5 & 3 & 1 & 2 \\
\hline 8 & 8 & 10 & 8 & 3 & 2 & 3 \\
\hline 9 & 8 & 20 & 2 & 3 & 3 & 1 \\
\hline 10 & 12 & 0 & 8 & 4 & 1 & 3 \\
\hline 11 & 12 & 10 & 2 & 4 & 2 & 1 \\
\hline 12 & 12 & 20 & 5 & 4 & 3 & 2 \\
\hline 13 & 16 & 0 & 5 & 5 & 1 & 2 \\
\hline 14 & 16 & 10 & 8 & 5 & 2 & 3 \\
\hline 15 & 16 & 20 & 2 & 5 & 3 & 1 \\
\hline 16 & 20 & 0 & 8 & 6 & 1 & 3 \\
\hline 17 & 20 & 10 & 2 & 6 & 2 & 1 \\
\hline 18 & 20 & 20 & 5 & 6 & 3 & 2 \\
\hline
\end{tabular}

In this step, the benevolent formulation (Eq. (3)) proposed by Doyle \& Green [51], is applied to estimate the optimal input and output weights, $v_{i k}^{*}$ and $u_{r k}^{*}$ as well as the optimal free variable, $v_{o k}^{*}$ chosen by each DMU. Once the optimal weights and free variables are determined, they are used to generate cross-efficiency scores for each $D M U_{j}$. The cross-efficiency scores are calculated using the expression given in Eq. (4). Thereafter, the generated cross-efficiency scores are used to construct the cross-efficiency matrix and to obtain the mean cross efficiency scores (MCES), $\theta_{j}$, for each $D M U_{j}$ (Eq. 5). The MCES for each $D M U_{j}$ is calculated as the arithmetic mean across each row. This is done to obtain the average appraisal of peers.

$$
\begin{aligned}
& \text { Minimize } 1 / \theta_{k k}=\sum_{j=1, j \neq k}^{n}\left(v_{0 k}+\sum_{i=1}^{m} v_{i k} x_{i k}\right) \\
& \text { Subject to } \sum_{j=1, j \neq k}^{n} \sum_{r=1}^{s} u_{r k} y_{r k}=1, \\
& v_{0 k}+\sum_{i=1}^{m} v_{i k} x_{i j}-\sum_{r=1}^{s} u_{r k} y_{r j} \geq 0, j=1, \ldots \ldots n, \\
& v_{0 k}+\sum_{i=1}^{m} v_{i k} x_{i k}-1 / \theta_{k k} \sum_{r=1}^{s} u_{r k} y_{r k}=0,
\end{aligned}
$$

$u_{r k} \geq \varepsilon, r=1 \ldots . s$ 
$v_{i k} \geq \varepsilon, i=1 \ldots \ldots m$

$v_{0 k}$ is unconstrained in sign

$$
\begin{aligned}
\theta_{k j} & =\frac{v_{o k}^{*}+\sum_{i=1}^{m} v_{i k}^{*} x_{i j}}{\sum_{r=1}^{s} u_{r k}^{*} y_{r j}}, k, j=1,2 \ldots, n \\
\theta_{j} & =\frac{1}{n} \sum_{j=1}^{n} \theta_{k j}
\end{aligned}
$$

Step 4: Parameter effect on the MCES.

The average efficiency scores for the various DMUs that appear on the same parameter level are determined in this last step. This is done by determining the level of any parameter level in which the MCES are maximized.

\section{Results and discussion}

\section{Effect of the process parameters on the responses}

The process parameter effect on the responses is displayed in Fig. 2. The result for the effect of the additives on the CBR in Fig. 2a suggests that changes in the quantity of the additives had a noticeable effect on the CBR. Judging from the maximum slope of the linear variations, the effect of the SDA was the most pronounced. The effect of the QD and OPC on the CBR appears to be roughly the same. As such, the quantity of the additive admixed with the soil for the three additives significantly influence the change in the CBR. For the UCS in Fig. 2b, it can be similarly concluded that the SDA had the most perceptible effect on the UCS based on the maximum slope. The effect of the OPC was also very pronounced, with the QD yielding the least effect on the UCS variation. The variation in DFS with change in the additives content is represented in Fig. 2c. The SDA clearly had the most significant effect on the DFS of the expansive soil. The effect of both QD and OPC appear to be less pronounced, with the maximum observed slope, typically having an effect below $10 \%$ in the DFS. The outcome of the result in Fig. 2 clearly indicates the influential role of the SDA in the expansive soil treatment. This could likely be due to its self-cementing ability as explicated subsequently.

\section{Optimal combination for individual responses}

The experiment data obtained from the study performed by Ikeagwuani [72] is presented in Table 5. Ikeagwuani [72] optimized the additives using the L18 Taguchi mixed level orthogonal array. The responses considered in the study were UCS, $\mathrm{CBR}$ and DFS. The values obtained for the responses after the optimization were $738.735 \mathrm{kN} / \mathrm{m}^{2}, 50.04$ and $3.69 \%$ for the UCS, CBR and DFS respectively. These values were found at three different conflicting combinations. The combinations were A3 B3 C3 (UCS), A6 B3 C3 (CBR) and A6 B3 C2 (DFS). This shows the ineffectiveness of Taguchi approach in the concurrent optimization of additives. In reality, geotechnical and highway engineers often seek to improve multiple properties of the soil. 

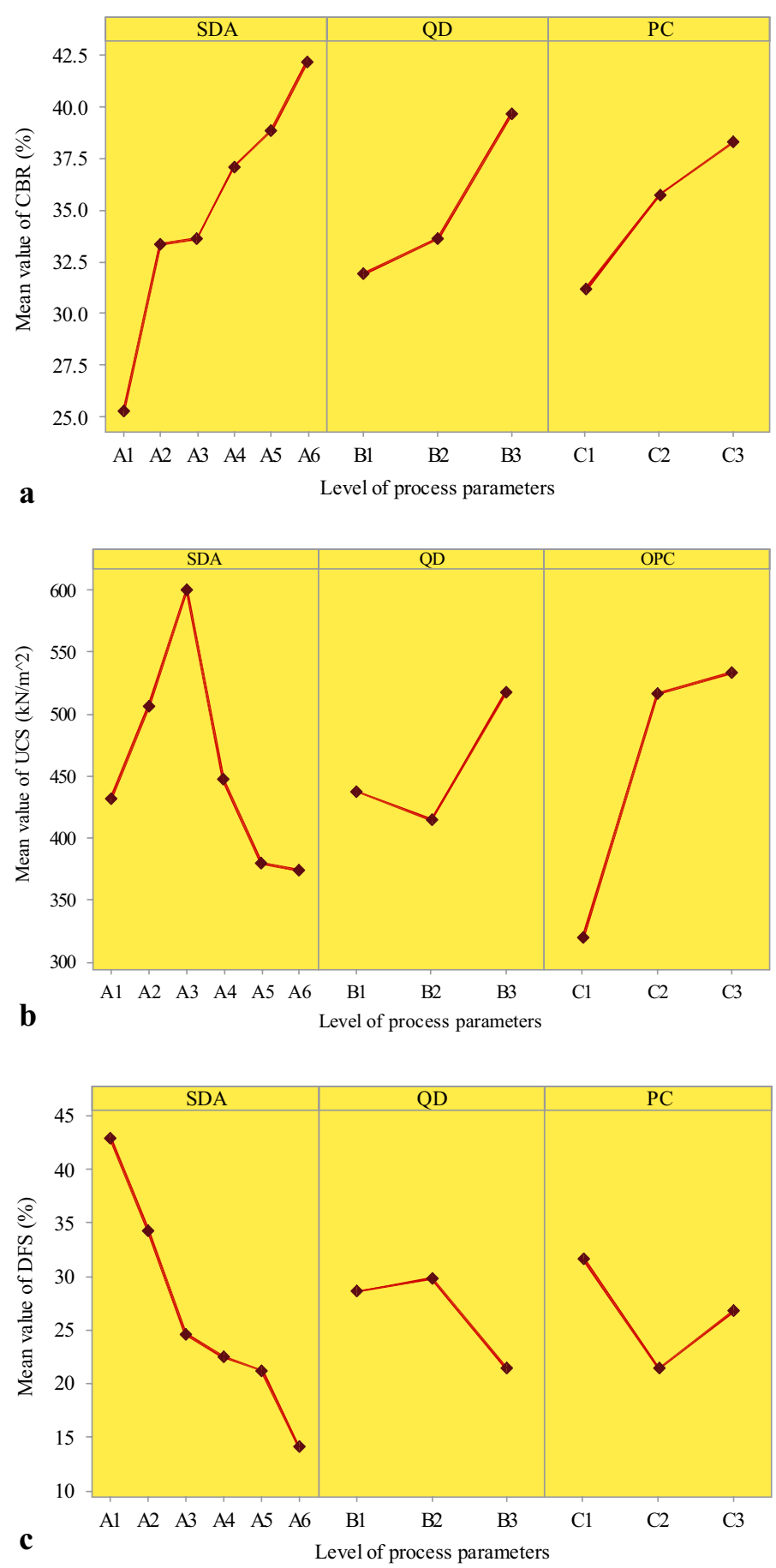

Fig. 2 Plots of process parameter effect on $\mathbf{a} C B R, \mathbf{b} \cup C S, \mathbf{c}$ DFS

Remarkably, this present study was used to optimize the ternary additives concurrently by integrating the output-oriented BCC model and the benevolent formulation into the Taguchi method for the enhancement of the expansive soil properties. 
Table 5 Experimental data

\begin{tabular}{llllllllllr}
\hline Expt. No & UCS & \multicolumn{7}{c}{ CBR } & \multicolumn{3}{c}{ DFS } \\
\hline 1 & 229.11 & 237.14 & 296.68 & 12.23 & 10.86 & 27.57 & 23.78 & 54.12 & 55.15 & 53.57 \\
2 & 407.75 & 361.60 & 459.05 & 26.22 & 30.58 & 21.77 & 24.35 & 45.18 & 45.98 & 44.38 \\
3 & 617.41 & 552.78 & 724.66 & 33.03 & - & 34.03 & 32.30 & 29.53 & 28.57 & 30.30 \\
4 & 363.08 & 246.20 & 171.18 & 21.61 & 23.70 & 19.70 & 25.44 & 43.30 & 43.93 & 42.70 \\
5 & 701.92 & 424.63 & 639.86 & 33.30 & 28.60 & 34.48 & 32.58 & 27.62 & 28.50 & 26.44 \\
6 & 644.39 & 698.88 & - & 46.23 & 45.43 & 45.95 & 43.42 & 32.00 & 31.12 & 33.33 \\
7 & 710.28 & 756.21 & 800.30 & 30.17 & 27.41 & 36.30 & 36.32 & 22.02 & 22.86 & 21.23 \\
8 & 674.93 & 526.44 & 441.33 & 26.76 & - & 19.69 & 51.19 & 32.67 & 31.66 & 33.15 \\
9 & 488.83 & 475.93 & 528.82 & 36.55 & 34.35 & 38.78 & 33.93 & 19.05 & 19.63 & 18.78 \\
10 & 513.51 & 634.70 & - & 35.10 & 31.95 & 22.50 & 31.23 & 31.82 & 32.50 & 30.69 \\
11 & 196.79 & 280.08 & 242.31 & 36.23 & 34.89 & 33.54 & 34.85 & 22.07 & 22.58 & 21.63 \\
12 & 660.80 & 633.02 & 286.96 & 49.22 & 44.39 & 48.20 & 43.50 & 13.64 & 14.81 & 12.89 \\
13 & 422.39 & 274.89 & 485.91 & 43.61 & 38.23 & 36.37 & 38.31 & 11.62 & 11.91 & 11.16 \\
14 & 453.29 & 324.02 & - & 43.19 & 37.66 & 42.30 & 37.18 & 26.52 & 27.32 & 25.74 \\
15 & 322.34 & 373.88 & 370.38 & 38.22 & 35.81 & 39.59 & 35.73 & 25.65 & 25.60 & 25.84 \\
16 & 399.71 & 429.12 & 335.22 & 55.93 & 51.79 & 38.05 & 48.55 & 8.70 & 9.75 & 7.63 \\
17 & 248.09 & 284.80 & 397.48 & 34.69 & - & 39.85 & 38.93 & 25.22 & 26.11 & 24.39 \\
18 & 462.49 & 417.59 & 393.78 & 38.36 & 36.46 & 53.78 & 32.43 & 8.43 & 8.37 & 8.30 \\
\hline
\end{tabular}

Table 6 Mean response values

\begin{tabular}{|c|c|c|c|c|c|c|c|}
\hline \multirow{2}{*}{$\begin{array}{l}\text { Experimental } \\
\text { runs }\end{array}$} & \multirow[t]{2}{*}{$D M U_{j}$} & \multicolumn{3}{|c|}{ Parameter } & \multirow[t]{2}{*}{ UCS $\left(k N / m^{2}\right)$} & \multirow[t]{2}{*}{ CBR (\%) } & \multirow[t]{2}{*}{ DFS $(\%$} \\
\hline & & SDA & QD & $\overline{O P C}$ & & & \\
\hline 1 & $\mathrm{DMU}_{1}$ & 0 & 0 & 2 & 254.33 & 18.61 & 54.28 \\
\hline 2 & $\mathrm{DMU}_{2}$ & 0 & 10 & 5 & 409.47 & 24.11 & 45.18 \\
\hline 3 & $\mathrm{DMU}_{3}$ & 0 & 20 & 8 & 631.62 & 33.12 & 29.47 \\
\hline 4 & $\mathrm{DMU}_{4}$ & 4 & 0 & 2 & 260.15 & 22.61 & 43.31 \\
\hline 5 & $\mathrm{DMU}_{5}$ & 4 & 10 & 5 & 588.81 & 32.24 & 27.52 \\
\hline 6 & $\mathrm{DMU}_{6}$ & 4 & 20 & 8 & 671.64 & 45.26 & 32.15 \\
\hline 7 & $\mathrm{DMU}_{7}$ & 8 & 0 & 5 & 755.60 & 32.55 & 22.04 \\
\hline 8 & $\mathrm{DMU}_{8}$ & 8 & 10 & 8 & 547.57 & 32.55 & 32.49 \\
\hline 9 & $\mathrm{DMU}_{9}$ & 8 & 20 & 2 & 497.86 & 35.90 & 19.15 \\
\hline 10 & $\mathrm{DMU}_{10}$ & 12 & 0 & 8 & 574.11 & 30.20 & 31.67 \\
\hline 11 & $\mathrm{DMU}_{11}$ & 12 & 10 & 2 & 239.73 & 34.88 & 22.09 \\
\hline 12 & $\mathrm{DMU}_{12}$ & 12 & 20 & 5 & 526.92 & 46.33 & 13.78 \\
\hline 13 & $\mathrm{DMU}_{13}$ & 16 & 0 & 5 & 394.40 & 39.13 & 11.56 \\
\hline 14 & $\mathrm{DMU}_{14}$ & 16 & 10 & 8 & 388.65 & 40.08 & 26.53 \\
\hline 15 & $\mathrm{DMU}_{15}$ & 16 & 20 & 2 & 355.53 & 37.34 & 25.70 \\
\hline 16 & $\mathrm{DMU}_{16}$ & 20 & 0 & 8 & 388.02 & 48.58 & 8.69 \\
\hline 17 & $\mathrm{DMU}_{17}$ & 20 & 10 & 2 & 310.12 & 37.82 & 25.24 \\
\hline 18 & $\mathrm{DMU}_{18}$ & 20 & 20 & 5 & 424.63 & 40.26 & 8.37 \\
\hline
\end{tabular}

\section{Application of VRS DEA and benevolent formulation to Taguchi approach for additives optimization}

The concurrent optimization of the additives was executed using a combination of DEA solver software and visual basic application (VBA) code as illustrated in the 
Table 7 BCC-efficiency of DMUs

\begin{tabular}{|c|c|c|c|c|c|c|c|}
\hline \multirow[t]{2}{*}{$D M U_{j}$} & \multicolumn{3}{|c|}{ Inputs } & \multicolumn{3}{|l|}{ Outputs } & \multirow{2}{*}{$\begin{array}{l}\text { BCC-efficiency, } \\
\theta_{k k}\end{array}$} \\
\hline & $x_{1 j}$ & $x_{2 j}$ & $x_{3 j}$ & $y_{1 j}$ & $y_{2 j}$ & $y_{3 j}$ & \\
\hline $\mathrm{DMU}_{1}$ & 0 & 0 & 2 & 254.33 & 18.61 & 54.28 & 1.00 \\
\hline $\mathrm{DMU}_{2}$ & 0 & 10 & 5 & 409.47 & 24.11 & 45.18 & 1.00 \\
\hline $\mathrm{DMU}_{3}$ & 0 & 20 & 8 & 631.62 & 33.12 & 29.47 & 1.00 \\
\hline $\mathrm{DMU}_{4}$ & 4 & 0 & 2 & 260.15 & 22.61 & 43.31 & 1.00 \\
\hline $\mathrm{DMU}_{5}$ & 4 & 10 & 5 & 588.81 & 32.24 & 27.52 & 1.00 \\
\hline $\mathrm{DMU}_{6}$ & 4 & 20 & 8 & 671.64 & 45.26 & 32.15 & 1.00 \\
\hline $\mathrm{DMU}_{7}$ & 8 & 0 & 5 & 755.60 & 32.55 & 22.04 & 1.00 \\
\hline $\mathrm{DMU}_{8}$ & 8 & 10 & 8 & 547.57 & 32.55 & 32.49 & 1.08 \\
\hline $\mathrm{DMU}_{9}$ & 8 & 20 & 2 & 497.86 & 35.90 & 19.15 & 1.00 \\
\hline $\mathrm{DMU}_{10}$ & 12 & 0 & 8 & 574.11 & 32.76 & 31.67 & 1.00 \\
\hline $\mathrm{DMU}_{11}$ & 12 & 10 & 2 & 239.73 & 34.88 & 22.09 & 1.00 \\
\hline $\mathrm{DMU}_{12}$ & 12 & 20 & 5 & 526.92 & 46.33 & 13.78 & 1.00 \\
\hline $\mathrm{DMU}_{13}$ & 16 & 0 & 5 & 394.340 & 39.13 & 11.56 & 1.00 \\
\hline $\mathrm{DMU}_{14}$ & 16 & 10 & 8 & 388.65 & 40.08 & 26.53 & 1.07 \\
\hline $\mathrm{DMU}_{15}$ & 16 & 20 & 2 & 355.53 & 37.34 & 25.70 & 1.00 \\
\hline $\mathrm{DMU}_{16}$ & 20 & 0 & 8 & 388.02 & 52.09 & 8.69 & 1.00 \\
\hline $\mathrm{DMU}_{17}$ & 20 & 10 & 2 & 310.12 & 37.82 & 25.24 & 1.00 \\
\hline $\mathrm{DMU}_{18}$ & 20 & 20 & 5 & 424.63 & 40.26 & 8.37 & 1.15 \\
\hline
\end{tabular}

Table 8 Optimal input and output weights

\begin{tabular}{|c|c|c|c|c|c|c|c|c|}
\hline \multirow[t]{2}{*}{$D M U_{j}$} & \multirow{2}{*}{$\begin{array}{l}\text { BCC-efficiency } \\
\theta_{k k}\end{array}$} & \multicolumn{3}{|c|}{ Input weights } & \multicolumn{3}{|c|}{ Output weights } & \multirow{2}{*}{$\begin{array}{l}\text { Free variable } \\
v_{o k}^{*}\end{array}$} \\
\hline & & $v_{1 k}^{*}$ & $v_{2 k}^{*}$ & $v_{3 k}^{*}$ & $u_{1 k}^{*}$ & $u_{2 k}^{*}$ & $u_{3 k}^{*}$ & \\
\hline $\mathrm{DMU}_{1}$ & 1.0000 & 0.00060 & 0.00053 & 0.00332 & 0.00001 & 0.00128 & 0.00027 & 0.03490 \\
\hline $\mathrm{DMU}_{2}$ & 1.0000 & 0.00066 & 0.00000 & 0.00000 & 0.00007 & 0.00000 & 0.00112 & 0.07756 \\
\hline $\mathrm{DMU}_{3}$ & 1.0000 & 0.00266 & 0.00000 & 0.00488 & 0.00007 & 0.00059 & 0.00024 & 0.03210 \\
\hline $\mathrm{DMU}_{4}$ & 1.0000 & 0.00064 & 0.00057 & 0.00351 & 0.00001 & 0.00131 & 0.00025 & 0.03365 \\
\hline $\mathrm{DMU}_{5}$ & 1.0000 & 0.00275 & 0.00038 & 0.00479 & 0.00004 & 0.00114 & 0.00000 & 0.02197 \\
\hline $\mathrm{DMU}_{6}$ & 1.0000 & 0.00062 & 0.00054 & 0.00343 & 0.00001 & 0.00133 & 0.00028 & 0.03609 \\
\hline $\mathrm{DMU}_{7}$ & 1.0000 & 0.00061 & 0.00053 & 0.00337 & 0.00001 & 0.00130 & 0.00028 & 0.03543 \\
\hline $\mathrm{DMU}_{8}$ & 1.0780 & 0.00000 & 0.00025 & 0.00000 & 0.00007 & 0.00000 & 0.00106 & 0.07513 \\
\hline $\mathrm{DMU}_{9}$ & 1.0000 & 0.00061 & 0.00053 & 0.00337 & 0.00001 & 0.00130 & 0.00028 & 0.03545 \\
\hline $\mathrm{DMU}_{10}$ & 1.0000 & 0.00000 & 0.00070 & 0.00089 & 0.00002 & 0.00094 & 0.00063 & 0.05485 \\
\hline $\mathrm{DMU}_{11}$ & 1.0000 & 0.00067 & 0.00050 & 0.00340 & 0.00001 & 0.00136 & 0.00028 & 0.03524 \\
\hline $\mathrm{DMU}_{12}$ & 1.0000 & 0.00059 & 0.00053 & 0.00340 & 0.00001 & 0.00131 & 0.00027 & 0.03659 \\
\hline $\mathrm{DMU}_{13}$ & 1.0000 & 0.00066 & 0.00116 & 0.00547 & 0.00001 & 0.00149 & 0.00005 & 0.02514 \\
\hline $\mathrm{DMU}_{14}$ & 1.0690 & 0.00000 & 0.00056 & 0.00000 & 0.00000 & 0.00108 & 0.00079 & 0.06287 \\
\hline $\mathrm{DMU}_{15}$ & 1.0000 & 0.00000 & 0.00014 & 0.00343 & 0.00003 & 0.00081 & 0.00055 & 0.04671 \\
\hline $\mathrm{DMU}_{16}$ & 1.0000 & 0.00062 & 0.00054 & 0.00343 & 0.00001 & 0.00132 & 0.00028 & 0.03606 \\
\hline $\mathrm{DMU}_{17}$ & 1.0000 & 0.00061 & 0.00054 & 0.00338 & 0.00001 & 0.00130 & 0.00028 & 0.03552 \\
\hline $\mathrm{DMU}_{18}$ & 1.1508 & 0.00000 & 0.00015 & 0.00424 & 0.00000 & 0.00167 & 0.00000 & 0.05331 \\
\hline
\end{tabular}

following steps:

Step 1: In this first step, the mean values of each response (Table 6) were obtained after defining the DMUs which included the inputs and outputs variables. There were 
three input variables, which were the three additives used by Ikeagwuani [72]. The inputs were SDA $\left(x_{1 j}\right)$, QD $\left(x_{2 j}\right)$ and OPC $\left(x_{3 j}\right)$. There were 18 different experiments in the Taguchi mixed level orthogonal array used in the study conducted by Ikeagwuani [72] and this corresponds to 18 different DMUs. The output variables, which were the responses, included UCS $\left(y_{1 j}\right)$, CBR $\left(y_{2 j}\right)$ and DFS $\left(y_{3 j}\right)$.

Step 2: In the second step, the BCC-efficiency for each DMU was calculated. The BCC-efficiency was calculated by using Eq. (2b) and the result is presented in Table 7 .

Step 3: In this step, optimal input and output weights for each DMU as well as the free variables were determined for each DMU using the benevolent formulation expressed in Eq. (3). The results are displayed in Table 8. Next, the cross-efficiency scores, which were used for the construction of the cross-efficiencies matrix, were estimated using Eq. (4) and the results are presented in Table 9. Thereafter, the MCES for each $D M U_{j}$ were determined using Eq. (5) and the results are shown in Table 9.

Step 4: The optimum combination of additives were determined in this last step. The MCES were determined for DMUs which are on the same parameter level. The parameter level that maximizes the MCES was adopted as the optimal level for that parameter. The results of the parameter level effect on the MCES are shown in Table 10 while the corresponding plots of the parameter level effect on the MCES are depicted in Fig. 3(a-c).

\section{Experimental validation}

The optimum combination of additives (A6 B2 C3) obtained from this study which involves the integration of VRS DEA and benevolent formulation into the Taguchi approach is absent in the experiment performed by Ikeagwuani [72]. This, therefore, necessitated the need to validate the proposed procedure through conducting confirmatory test. To conduct the confirmatory test, the optimum combination of additives was thoroughly blended with the expansive soil. The soil samples used for the UCS test were subjected to $28 \mathrm{~d}$ curing while the samples used for the unsoaked CBR confirmatory test were cured for $7 \mathrm{~d}$. Both samples were cured in a humidity-controlled environment. The result obtained from the confirmatory test is presented in Table 11. Furthermore, other additives combinations close to the obtained optimum were also tested in the laboratory for confirmation. This was done to evaluate more closely, the uniqueness of the obtained optimal solution as the global optimal solution. The comparative test results are summarized in Table 12. For the concurrent optimization of the UCS, CBR and DFS, the achieved optimal solution based on the VRS DEA exhibited a superior performance.

In order to verify the suitability of the predicted responses from the VRS DEA Taguchi model, the predicted values and the values obtained from the experimental confirmatory test are shown in Table 13. It can be deduced that the VRS DEA Taguchi model slightly under predicted the responses, which is considered conservative. Moreover, the absolute percentage error values between the experimental and predicted responses are quite low, which provides further justification of the prediction accuracy; especially for the CBR that is a crucial pavement design parameter for subgrade and unbound granular materials. 


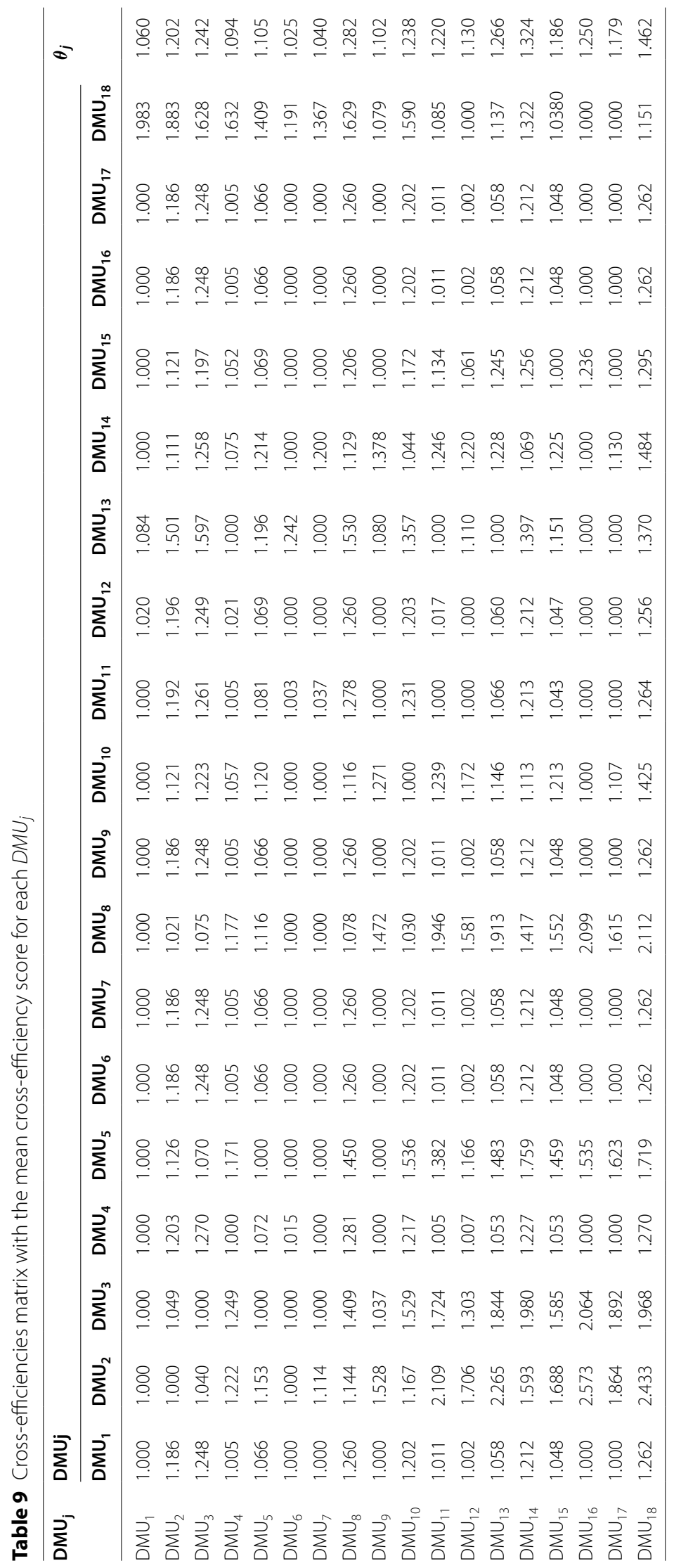


Table 10 Parameter effect on the mean cross-efficiency scores

\begin{tabular}{llllllll}
\hline Parameter & $\begin{array}{l}\text { Physical } \\
\text { meaning }\end{array}$ & Level & & & & \\
& & 1 & 2 & 3 & 4 & 5 & $\mathbf{6}$ \\
A & SDA & 1.168 & 1.075 & 1.141 & 1.196 & 1.259 & $\mathbf{1 . 2 9 7}$ \\
B & QD & 1.158 & $\mathbf{1 . 2 1 9}$ & 1.191 & & & \\
C & OPC & 1.140 & 1.201 & $\mathbf{1 . 2 2 7}$ & & & \\
\hline
\end{tabular}

Key: Values in bold colour represents optimal parameter level

\section{Enhancement mechanism of the additives}

\section{$O P C$}

The use of OPC as a cementing material is well established. The mechanisms of cementation often occur through both immediate strength gains on hydration and long term pozzolanic reactions. These ultimately result to the formation of cementitious compounds, mainly the $\mathrm{CSH}$ phases [85]. The formed compounds act as binding agents due to the cementation bonds formed. As shown in Table 2, the major chemical composition of the OPC is the $\mathrm{CaO}$ that is inherent in the active components of the OPC. These active components, which are principally responsible for its cementation reactions are the alite and belite.

$Q D$

Quarry dusts are particles, mainly in granular form, which are known to improve the physical texture of any material blended with it. Quarry dust is often characterized by high specific gravity which imparts higher density [86] with potential for strength improvement. It is known to posses high shear strength and further improves the gradation of fine-grained soils, giving the soil a coarse granular and friction resistant structure $[87,88]$. Moreover, it possesses fine fractions, which makes it a very good filler material that improves the soil pore structure [89]. The presence of significant amounts of $\mathrm{SiO}_{2}$ and $\mathrm{AlO}_{2}$ in its oxide composition (Table 2) further suggests that it is capable of partaking in pozzolanic reactions for the formation of cementitious compounds.

$S D A$

The SDA consist of extremely fine particles, which are rich in $\mathrm{SiO}_{2}, \mathrm{CaO}$ and $\mathrm{K}_{2} \mathrm{O}$ (Table 2). The presence of $\mathrm{SiO}_{2}$ and $\mathrm{CaO}$ is a good indication of self-cementation ability [90] and thus can partake in pozzolanic reactions [91]. Moreover, the presence of $\mathrm{K}_{2} \mathrm{O}$ and $\mathrm{CaO}$ indicates a good ionization potential for cation exchange as $\mathrm{K}^{+}$and $\mathrm{Ca}^{2+}$ ions are exchangeable cations in the diffuse double layer of clays. As such, they possess the ability to initiate cation exchange process in clay minerals. The cation exchange process of $\mathrm{Ca}^{2+}$ causes flocculation, which makes the soil particles to be friable with higher potential for strength increment $[2,92]$. In the case of kaolin-rich soils, ionization of $\mathrm{K}^{+}$ ions can facilitate the formation of K-feldspar, which imparts strength to the soil [93]. Moreover, for expansive soils rich in montmorillonite, the potential for clay mineral modification is expected due to the ionization of the potash present in the SDA. 

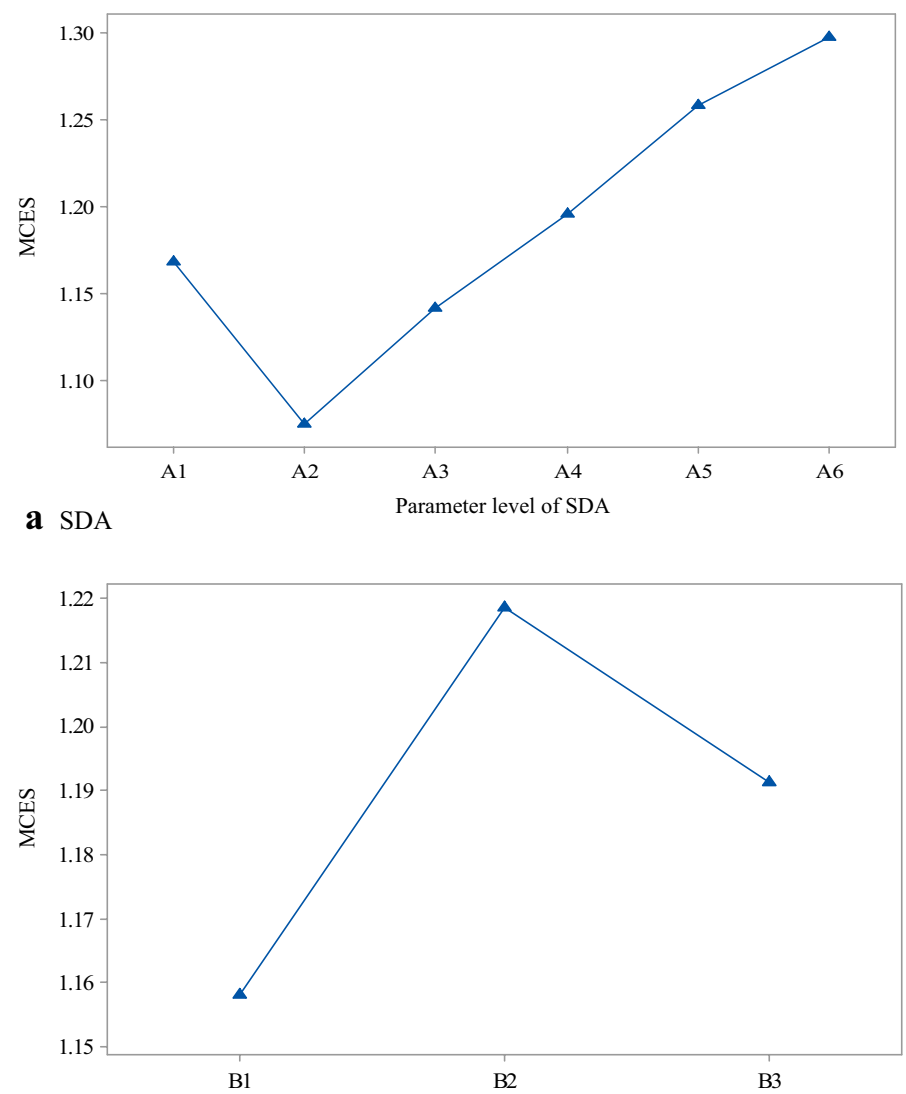

b QD Parameter level of QD

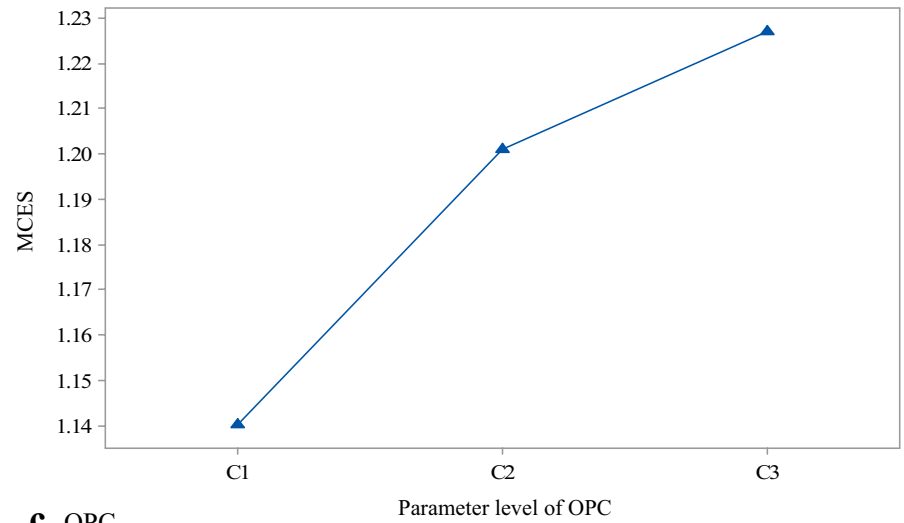

Fig. 3 a-c Plots of parameter level effect on MCES

Table 11 Optimum combination of additives with their corresponding responses

\begin{tabular}{lll}
\hline Response & Optimum combination & Mean responses value \\
\hline UCS & A6 B2 C3 & $864.31 \mathrm{kN} / \mathrm{m}^{2}$ \\
CBR & A6 B2 C3 & $60.45 \%$ \\
DFS & A6 B2 C3 & $5.34 \%$ \\
\hline
\end{tabular}


Table 12 Comparison of optimal combination with other close combinations

\begin{tabular}{llllr}
\hline S/N & Combination & UCS $\left(\mathbf{k N} / \mathbf{m}^{2}\right)$ & CBR (\%) & DFS (\%) \\
\hline 1 & A6 B2 C3* & $864.31^{*}$ & $60.45^{*}$ & $5.34^{*}$ \\
2 & A6 B1 C2 & 854.476 & 48.91 & 25.38 \\
3 & A6 B3 C3 & 729.314 & 48.58 & 3.26 \\
4 & A6 B2 C2 & 889.281 & 44.50 & 20.25 \\
\hline
\end{tabular}

* Represents the optimal combination

Table 13 Comparison of experimental and predicted values of the responses obtained from VRSDEA Taguchi optimization

\begin{tabular}{lccl}
\hline Response & Experimental & Predicted & Absolute \% error \\
\hline CBR $(\%)$ & 60.45 & 53.96 & 0.107 \\
UCS $\left(\mathrm{kN} / \mathrm{m}^{2}\right)$ & 864.31 & 758.68 & 0.122 \\
DFS $(\%)$ & 5.34 & 7.53 & 0.410 \\
\hline
\end{tabular}

\section{Optimum combination of additives effect on UCS, CBR and DFS}

UCS

A significant change in the UCS was prevalent due to the addition of the optimum combination of additives to the soil. The UCS of the soil increased from an initial value of $152.5 \mathrm{kPa}$ to a value of about $864.3 \mathrm{kPa}$, which represents an increment of $467 \%$. The improvement can be explicated in terms of micro and macro level changes occasioned by the physical and chemical actions of the additives on the soil-additives matrix. The physical action of the QD particles resulted in physical modification through imparting an improved gradation and coarse-granular nature to the soil. This resulted in a more intense interlocking of the particles with higher shear resistance, which is a known characteristic of QD particles as per previous studies [14, 87].

The chemical actions which modified the soil microstructure were due to hydration and pozzolanic reactions of the cement and additives particles (SDA and QD), which are pozzolanic materials. The hydration reaction led to instant strength gain, while the pozzolanic reaction resulted in long-term strength gain. On addition of water to the soil additives mixture, hydration reaction is initiated due to the active chemical compounds in the cement, principally dicalcium silicate and tricalcium silicate [85]. This resulted in the formation of a metastable form of paste known as portlandite as shown in reaction Eq. 6 [85].

$$
\begin{aligned}
& \left.2\left(3 \mathrm{Ca} \cdot \mathrm{SiO}_{2}\right)+6 \mathrm{H}_{2} \mathrm{O} \rightarrow 3 \mathrm{CaO} \cdot 2 \mathrm{SiO}_{2} \cdot 3 \mathrm{H}_{2} \mathrm{O}+3 \mathrm{Ca}(\mathrm{OH})_{2}\right) \\
& 2\left(2 \mathrm{Ca} \cdot \mathrm{SiO}_{4}\right)+4 \mathrm{H}_{2} \mathrm{O} \rightarrow 3 \mathrm{CaO} \cdot 2 \mathrm{SiO}_{2} \cdot 3 \mathrm{H}_{2} \mathrm{O}+\mathrm{Ca}(\mathrm{OH})_{2}
\end{aligned}
$$

The portlandite reacts with the nano particles of silica and alumina present in the QD and SDA to form binding complexes, mainly those of $\mathrm{C}-\mathrm{S}-\mathrm{H}$ and $\mathrm{C}-\mathrm{A}-\mathrm{H}$ nanophases. Different binding phases of C-S-H can be formed such as the $\alpha-\mathrm{C}-\mathrm{S}-\mathrm{H}, \beta-\mathrm{C}-\mathrm{S}-\mathrm{H}$ and $\gamma-\mathrm{C}-\mathrm{S}-\mathrm{H}$, depending on the $\mathrm{Ca} / \mathrm{Si}$ ratio [94]. The properties of these nanostructures can reflect the changes in the macro level behavior of the soil-additives matrix [9496]. The binding complexes crystallize further with time to form denser particles such 
as globules, which can favorably seal the pores in the soil, thereby improving the soil strength as moisture ingress is impeded. Similar findings have been reported in other studies [20,97].

During the curing period of the samples, pozzolanic reaction occurred, which further led to strength gain. Due to the presence of calcium and silicon oxides in the soil-additives mixture, $\mathrm{C}-\mathrm{S}-\mathrm{H}$ forms in the presence of moisture. With time, condensation of the $\mathrm{C}-\mathrm{S}-\mathrm{H}$ occurs in a similar way as the sol gel process of inorganic gels. Denser particles then result from the polymerization process which further imparted a higher strength to the soil through flocculation and agglomeration [95, 98-100].

\section{CBR}

The CBR showed considerable increment from a value of $9.4-60.5 \%$ due to the addition of optimum combination of additives to the soil. This shows an increase in CBR by as much as 544\%. The physical action of the QD particles made the soil-additives matrix resistant to penetration because of the coarse-grained nature imparted to the soil. Furthermore, the fine particles in the QD acted as microfillers to fill up void spaces in the soil which facilitated compaction to achieve higher density. This also made the soil-additives matrix resistant to the penetrative force of the CBR plunger.

Chemical action occurred in the soil-additives matrix due to the presence of potash in the SDA particles which transformed the structure of the soil clay mineral. Dissolution of the potash in the presence of moisture, releases $\mathrm{K}^{+}$ions which are exchangeable with the weak hydrous ions of the adsorbed water in the diffuse double layer. This chemical action modifies the structure of montmorillonite clay mineral in the soil to that of illite due to affixation of $\mathrm{K}^{+}$ions in the clay interlayer. Illite clay has less affinity for moisture and hence more stable [101-103], which also explains the reason for the higher strength achieved.

\section{DFS}

On addition of the optimum combination of additives, the soil showed a minimal tendency to swell, as the DFS greatly declined from a value of $71.6-5.3 \%$. This shows a tremendous drop of about $1251 \%$ in the DFS. The change in the swelling behavior is adduced to the physical and chemical actions of the additives. In addition to the lubrication of the fine particles of the additives with increased surface area, the chemical reactions which took place used up a substantial amount of the available moisture. Hence uptake of water for swelling greatly dropped. Also, the likelihood of swelling has been reported to drop in the presence of granular materials such as the QD particles [88, 104].

In a related development, the cation exchange process of higher valence cations like

the $\mathrm{Ca}^{2+}$ balanced the ionic charge concentration within the clay-pore fluid media; and with the formation of cementitious compounds, the clay layer is made more stable. This in essence, resulted to the lower moisture affinity and drop in swelling observed. Similar observations have also been reported elsewhere $[105,106]$. More so, the hydrophilic nature of the soil was further altered by the flocculation and agglomeration which occurred during the curing period, in addition to the clay mineral transformation previously explained. The volume change behavior of the soil is controlled due to flocculation and agglomeration phenomenon [106]. 


\section{Conclusion}

This study was used to integrate output-oriented VRS-DEA and benevolent formulation in Taguchi approach in order to optimize additives for the enhancement of expansive soil properties. The integration was done because Taguchi approach alone is incapable of optimizing multiple additives for expansive soil properties. After the optimization process, confirmatory experiments were conducted by blending the expansive soil with the optimum combination of additives. Based on the results obtained from the optimization process and the confirmatory test performed thereafter, the following conclusions can be drawn:

1. Significant improvement in the expansive soil was found when a combination of $20 \%$ SDA, 10\% QD and 8\% OPC (A6 B2 C3) were blended with it.

2. The DFS of the expansive soil, which reduced considerably when the optimum combination of additives was added to it, was adduced to the interplay between the micro-filler effect experienced in the mixture which was driven by the presence of the QD and the cementitious compound formation in the soil-additive matrix.

3. The CBR of the expansive soil that was combined with the optimum combination of additives increased significantly apparently due to the improved mechanical strength of the soil. The improved mechanical strength aroused from the micro-filler effect experienced between the reaction of the QD and the soil. Furthermore, cation exchange effect caused by the reaction between ionized potash in the SDA and the montmorillonite clay mineral also contributed to the significant improvement in the CBR.

4. The remarkable increase recorded in the UCS value when the optimum combination of additives was added to the expansive soil was attributed to the artificial formation of cementitious compound in the mixture. The cementitious compound was formed when the expansive soil reacted with hydrated SDA. Other factors that contributed to the increase in the value of the UCS included the formation of water-cement paste that was observed when the OPC reacted with the soil and the high resistance to shear exerted by the QD

5. Lastly, the output-oriented VRS model combined with the benevolent formulation and integrated into Taguchi method has shown that it is capable to optimize ternary additives for the enhancement of expansive soil

Acknowledgements

The authors wish to acknowledge the immeasurable contributions of the anonymous reviewers of this manuscript that greatly assisted in the improvement of its clarity.

\section{Authors' contributions}

$\mathrm{CCl}$ and DCN conceived and designed the experiment. CCl financed and performed the experiment, $\mathrm{CCl}$ worked on most of the technical details and implemented the numerical analysis. CCI and DCN contributed to the interpretation of experimental results. Both authors read and approved the final manuscript

\section{Competing interests}

The authors declare that they have no competing interests.

Received: 16 July 2020 Accepted: 15 March 2021

Published online: 08 July 2021 
References

1. Ikeagwuani CC, Obeta IN, Agunwamba JC (2019) Stabilization of black cotton soil subgrade using sawdust ash and lime. Soils Found 59(1):162-175

2. Nwonu DC, Ikeagwuani CC (2019) Evaluating the effect of agro-based admixture on lime-treated expansive soil for subgrade material. Int J Pavement Eng. https://doi.org/10.1080/10298436.2019.1703979

3. Murad MA, Moyne C (2008) A dual-porosity model for ionic solute transport in expansive clays. Comput Geosci 12:47-82

4. Al-Mukhtar M, Khattab S, Alcover JF (2012) Microstructure and geotechnical properties of lime-treated expansive clayey soil. Eng Geol 139-140:17-27

5. Cristelo N, Glendinning S, Fernandes L, Pinto AT (2013) Effects of alkaline-activated fly ash and Portland cement on soft soil stabilisation. Acta Geotech 8:393-405

6. Horpibulsuk S, Rachan R, Suddeepong A (2011) Assessment of strength development in blended cement admixed Bangkok clay. Constr Build Mater 25:1521-1531

7. Ikeagwuani CC (2016) Compressibility characteristics of black cotton soil admixed with sawdust ash and lime. Niger J Technol 35(4):718-725

8. Ikeagwuani CC, Nwonu DC (2019) Emerging trends in expansive soil stabilisation: a review. J Rock Mech Geotech Eng 11:423-440

9. Latifi N, Rashid ASA, Siddiqua S, Horpibulsuk S (2015) Micro-structural analysis of strength development in low and high swelling clays stabilized with magnesium chloride solution-a green soil stabilizer. Appl Clay Sci 118:195-206

10. Saride S, Puppala AJ, Chikyala SR (2013) Swell-shrink and strength behaviors of lime and cement stabilized expansive organic clays. Appl Clay Sci 85:39-45

11. Yazdandoust F, Yasrobi S (2010) Effect of cyclic wetting and drying on swelling behavior of polymer-stabilized expansive clays. Appl Clay Sci 50:461-468

12. Estabragh AR, Pereshkafti MR, Parsaei B, Javadi AA (2012) Stabilised expansive soil behaviour during wetting and drying. Int J Pavement Eng 1-10

13. Estabragh AR, Rafatjo H, Javadi AA (2014) Treatment of an expansive soil by mechanical and chemical techniques. Geosynth Int 21(2):233-243

14. Onyelowe K, Igboayaka C, Orji F, Ugwuanyi H, Van DB (2019) Triaxial and density behaviour of quarry dust based geopolymer cement treated expansive soil with crushed waste glasses for pavement foundation purposes. Int $J$ Pavement Res Technol 12:78-87

15. Soltani A, Deng A, Taheri A, Mirzababaei M (2017) A sulphonated oil for stabilization of expansive soils. Int J Pavement Eng 1-14

16. Kampala A, Horpibulsuk S, Prongmanee N, Chinkulkijniwat A (2014) Influence of wet-dry cycles on compressive strength of calcium carbide residue - fly ash stabilized clay. J Mater Civ Eng 26:633-643

17. Latifi N, Horpibulsuk S, Meechan C, Abd-Majid MZ, Tahir MM, Mohamad ET (2017) Improvement of problematic soils with biopolymer — an environmentally friendly soil stabilizer. J Mater Civ Eng 29(2):1-11

18. Puppala AJ, Griffin JA, Hoyos LR, Chomtid S (2004) Studies on sulfate-resistant cement stabilization methods to address sulfate-induced soil heave. J Geotech Geoenviron Eng 130(4):391-402

19. Sivapullaiah PV, Sridharan A, Ramesh HN (2000) Strength behaviour of lime-treated soils in the presence of sulphate. Can Geotech J 37(6):1358-1367

20. Liu Y, Chang C, Namdar A, She Y, Lin C, Yuan X, Yang Q (2019) Stabilisation of expansive soil using cementing material from rice husk ash and calcium carbide residue. Constr Build Mater 221:1-11

21. Phanikumar BR, Raju ER (2020) Compaction and strength characterisitcs of an expansive clay stabilised with lime sludge and cement. Soils Found. https://doi.org/10.1016/j.sandf.2020.01.007

22. Ijaz N, Fuchu D, Chao ML, Rehman ZU, Qui ZH (2020) Integrating lignosulphonate and hydrated lime for the amelioration of expansive soil: a sustainable waste solution. Clean Prod. https://doi.org/10.1016/j.jclepro.2020.119985

23. Olgun M (2013) The effects and optimization of additives for expansive clays under freeze-thaw conditions. Cold Reg Sci Technol 93:36-46

24. Shahbazi M, Rowshanzamir M, Abtahi SM, Hejazi SM (2017) Optimization of carpet waste fibres and steel slag particles to reinforce expansive soil using response surface methodology. Appl Clay Sci 142(15):185-192

25. Taguchi G (1986) Introduction to quality engineering. Asian productivity organization, Tokyo

26. Phadke MS (1989) Quality engineering using robust design. PT R Prentice-Hall Inc, New Jersey

27. Park K, Ahn JH (2004) Design of experiment considering two-way interactions aand its application to injection molding processes with numerical analysis. J Mater Process Technol 146(2):221-227

28. Rao RS, Kumar CG, Prakasham RS, Hobbs PJ (2008) The Taguchi methodology as a statistical tool for biotechnological applications: a critical appraisal. Biotechnol J 3(4):510-523

29. Voelkel JG (2014) Fractional factorial designs, issues in, Wiley statsref: Statistics reference online, pp 1-13. Doi: https://doi.org/10.1002/9781118445112.stat04079

30. Shahavi MH, Hosseini M, Jahanshahi M, Meyer RL, Darzi GN (2015) Clove oil nanoemulsion as an effective antibacterial agent: Taguchi optimization method. Desalin Water Treat. https://doi.org/10.1080/19443994.2015.1092893

31. Mohammadi T, Kazemi P (2014) Taguchi optimization approach for phenolic wastewater treatment by vacuum membrane distillation. Desalin Water Treat 52(7-9):1341-1349

32. Azizi SN, Asemi N (2010) Parameter optimization of the fungicide (Vapam) sorption onto soil modified with clinoptilolite by Taguchi method. J Environ Sci Health B 45:766-773

33. Ai L, Zhang G, Li W, Liu G, Liu Q (2018) Optimization of radial-type superconducting magnetic bearing using the Taguchi method. Physica C (Amsterdam, Neth) 550:57-64

34. Chen K, Kao J, Hsu C, Hong P (2019) Multi-response optimization of mechanical properties for ZrWWN films grown using grey Taguchi approach. Ceram Int 45:327-333

35. Elcioglu EB, Yazicioglu G, Turgut A, Anagun AS (2018) Experimental study and Taguchi analysis on alumina-water nanofluid viscosity. Appl Therm Eng 128:973-981 
36. Mustafai FA, Balouch A, Jalbani N, Bhanger MI, Jagirani MS, Kumar A, Tunio A (2018) Microwave-assisted synthesis of imprinted polymer for selective removal of arsenic from drinking water by Taguchi statistical method. Eur Polymer J 133-142:109

37. Shu L, Yang M, Zhao H, Li T, Yang L, Zou X, Li Y (2019) Process optimization in a stirred tank bioreactor based on CFD-Taguchi method: A case study. J Clean Prod 230:1074-1084

38. Yu B, Liu Y (2018) Improvement in phase purity and yield of hydrothermally synthesized smectite using Taguchi method. Appl Clay Sci 161:103-109

39. Canbolat AS, Bademlioglu AH, Arslanoglu N, Kaynakli O (2019) Performance optimization of absorption refrigeration systems using Taguchi, ANOVA and grey relational analysis methods. J Clean Prod 229:874-885

40. Jajimoggala S, Dhananjay R, Lakshimi VVK (2019) Multi-response optimization of hot extrusion process parameters using FEM and grey relation based Taguchi method. Materials Today Proc 18(1):389-401

41. Kumar S, Singh R (2019) Optimization of process parameters of metal inert gas welding with preheating on AISI 1018 mild steel using grey based Taguchi method. Measurement 148:1-12. https://doi.org/10.1016/j.measu rement.2019.106924

42. Li Y, Zhu L (2019) Optimization of user experience in mobile application design by using a fuzzy analytic-networkprocess-based Taguchi method. Appl Soft Comput 79:268-282

43. Nagaraju N, Venkatesu S, Ujwala NG (2018) Optimization of process paramters of EDM process using Fuzzy logic and Taguchi methods for improving material removal rate and surface finish. Materials today: Proc 5(2):7420-7428

44. Prusty JK, Pradhan B (2020) Multi-response optimization using Taguchi-grey relational analysis for composition of flys ash-granulated blast furnace slag based geopolymer concrete. Constr Build Mater 24:1-17. https://doi.org/10 1016/j.conbuildmat.2020.118049

45. Vaghela PA, Prajapati JM (2019) Hybridization of Taguchi and genetic algorithm to minimize iteration for optimization of solution. MethodsX 6:230-238

46. Wakchaure KN, Thakur AG, Gadakh V, Kumar A (2018) Multi-objective optimization of friction stir welding of aluminium alloy 6068-T6 using hybrid Taguchi-grey relation analysis-ANN method. Materials Today Proc 5(2):7150-7159

47. Al-Refaie A, Al-Tabat MD (2011) Solving the multi-response problem in Taguchi method by benevolent formulation in DEA. J Intell Manuf 22:505-521

48. Charnes A, Cooper WW, Rhodes E (1978) Measuring the efficient of decision making units. Eur J Oper Res 2:429-444

49. Charnes A, Cooper WW, Lewin AY, Seiford LM (1994) Data envelopment analysis: theory, methodology and application. Kluwer Academic Publishers, New York

50. Sexton TR, Sikman RH, Hogan AJ (1986) Data Envelopment Analysis: Critique and Extensions. New Dir Program Eval 32:73-105. https://doi.org/10.1002/ev.1441

51. Doyle J, Green R (1994) Efficiency and cross-efficiency in DEA: derivations, meaning and uses. J Oper Res Soc 45:567-578

52. Cook WD, Zhu J (2015) DEA cross efficiency. In: Zhu J (ed) Data enveopment analysis. Springer, New York

53. Wang YM, Chin KS (2010) A neutral DEA model for cross-efficiency evaluation and its extension. Expert Syst Appl 37(5):3666-3675

54. Lim S (2012) Minmax and maxmin formulations of cross-efficiency in DEA. Comput Ind Eng 62(3):101-108

55. Jahanshahloo GR, Hosseinzadeh LF, Yafari Y, Madahi R (2011) Selecting symmetric weights as a secondary goal in DEA cross-efficiency evaluation. Appl Math Model 35(1):544-549

56. Lim R, Zhu J (2015) DEA cross-efficiency evaluation under variable returns to scale. J Oper Res Soc 66:476-487

57. Kao C, Liu ST (2020) A slacks-based measure model for calculating cross efficiency in data envelopment analysis. Omega. https://doi.org/10.1016/j.omega.2020.102192

58. Wu J, Chu JF, Sun JS, Zhu QY, Liang L (2016) Extended secondary gaol models for weights selection in DEA crossefficiency evaluation. Comput Ind Eng 93:143-151

59. Liang L, Wu J, Cook WD, Zhu J (2008) The DEA game cross efficiency model and its Nash equilibrium. Oper Res 56:1278-1288

60. Liu ST (2018) A DEA ranking method based on cross-efficiency intervals and signal-to-noise ratio. Ann Oper Res 216:207-232

61. Ramon N, Ruiz JL, Sirvent I (2014) Dominance relations and ranking of units by using interval number ordering with cross-efficiency intervals. J Oper Res Soc 65:1336-1343

62. Yang F, Ang S, Xia Q, Yang C (2012) Ranking DMUs by using interval DEA cross efficiency matrix with acceptability analysis. Eur J Oper Res 223:483-488

63. Wu J, Liang L, Yang F (2009) Achievement and benchmarking of countries at the summer olympics using cross efficiency evaluation method. Eur J Oper Res 197:722-730

64. Wu J, Yan H, Liu J (2009) Groups in DEA based cross-evaluation: An application to Asian container ports. Marit Policy Manag 36(6):545-558

65. Lim S, Oh KW, Zhu J (2014) Use of DEA cross-efficiency evaluation in portfolio selection: an application to Korean stock market. Eur J Oper Res 236:361-368

66. Gavgani SS, Zohrehbandian M (2014) "A cross-efficiency based ranking method for finding the most efficient DMU. Math Problems Eng. https://doi.org/10.1155/2014/269768

67. Sun Y, Huang H, Zhou C (2016) DEA game cross-efficiency model to urban public infrastructure investment comprehensive efficiency of China. Math Problems Eng. https://doi.org/10.1155/2016/9814313

68. Banker RD, Charnes A, Cooper WW (1984) Some models for estimating technical and scale inefficiencies in data envelopment analysis. Manage Sci 30:1078-1092

69. Cooper W, Seiford L, Tone K (2002) Data envelopment analysis: a comprehensive test with models, applications, references and DEA-Solver software. Kluwer academic publishers, New York

70. Zhu J (2014) Quantitative models for performance evaluation and benchmarking: data envelopment analysis with spreadsheets, 3rd edn. Springer Cham Heidelberg, New York 
71. Charnes A, Cooper WW (1962) Programming with linea fractional functionals. Nav Res Logist Q 9:181-186

72. Ikeagwuani CC (2019) Optimisation of additives for expansive soil reinforcement. Unpublished PhD thesis, 2019.

73. Garg SK (2011) Soil mechanics and foundation engineering. Khana Publishers, Nai Sarak

74. Holtz WG, Gibbs HJ (1956) Engineering properties of expansive clays. Trans Am Soc Civil Eng 121(1):641-663

75. AASHTO (1986) Standard specification for transportation materials and methods of sample and testing, 14th edn. American Association of State Highway and Transportation Officials, Washington, DC

76. Febin GK, Abhirami A, Vineetha AK, Manisha V, Ramkrishnan R, Sathyan D, Mini KM (2019) Strength and durability properties of quarry dust powder incorporated concrete blocks. Constr Build Mater 228:1-9

77. Zou G, Xu J, Wu C (2013) Feasibility study of using quarry waste for pavement application and its optimization. Int J Pavement Res Technol 6(3):175-183

78. Rezende LR, Silveira LR, Araujo WL, Luz MP (2014) Reuse of fine quarry wastes in pavement: case study in Brazil. J Mater Civ Eng ASCE 26(8):1-9

79. Zhao Y, Qiu J, Xing J, Sun X (2010) Recyling of quarry dust for supplementary cementitious materials in low carbon cement. Constr Build Mater. https://doi.org/10.1016/j.conbuildmat.2019.117608

80. Onyelowe K, Alaneme G, Igboayaka C, Orji F, Ugwuanyi H, Van DB, Van MN (2019) Scheffe optimisation of swelling, Californai bearing ratio, compressive strength and durability potentials of quarry dust stabilised soft clay soil. Mater Sci Energy Technol 2(1):67-77

81. Rezende LR, Carvalho C (2003) The use of quarry waste on pavement construction. Resour Conserv Recycl 39(1):91-105

82. BS 1377 (1990) Method of testing soils for civl engineering purposes. British Standard Institution, London

83. IS 2720 Part 40 (1977) Indian Standards method of test for soils. Bureau of Indian standards, New Delhi

84. Bristish Standard Institute (1990) Methods of testing soils for civil engineering purposes, London: BS 1377, Part 4

85. Bullard JW, Jennings HM, Livingston RA, Nonat A, Scherer GW, Schweitzer JS, Scrivener KL, Thomas JJ (2011) Mechanisms of cement hydration. Cem Concr Res 41:1208-1223

86. Nweke OM, Okogbue CO (2017) The potential of cement stabilized shale quarry dust for possible use as road foundation material. Int J Geo-Eng 8:29

87. Soosan TG, Sridharan A, Jose BT, Abraham BM (2005) Utilization of quarry dust to improve the geotechnical properties of soils in highway construction. Geotech Test J 28(4):1-10

88. Nwaiwu CM, Mshelia HS, Durkwa JK (2012) Compactive effort influence on properties of quarry dust-black cotton soil mixtures. Int J Geotech Eng 6:91-101

89. Nwonu DC, Ikeagwuani CC (2020) Microdust effect on the physical condition and microstructure of tropical black clay. Int J Pavement Res Technol 14(1):73-84

90. Edeh JE, Ugama T, Okpe SA (2018) The use of cement treated reclaimed asphalt pavement-quarry waste blends as highway material. Int J Pavement Eng 21(10):1-8

91. Butt WA, Gupta K, Jha JN (2016) Strength behavior of clayey soil stabilized with saw dust ash. Int J Geo-Eng 7:18

92. Firoozi AA, Olgun GC, Firoozi AA, Baghini MS (2017) Fundamental of soil stabilization. Int J Geo-Eng 8(26):1-16

93. Ikeagwuani CC (2019) Comparative assessment of stabilization of lime-stabilized lateritic soil as subbbase material using coconut shell ash and coconut hust ash. Geotech Geol Eng 37(4):3065-3076

94. Nonat A (2004) The structure and stoichiometry of C-S-H. Cem Concr Res 34:1521-1528

95. Jennings HM (2008) Refinements to colloid models of C-S-H in cement: CM-II. Cem Concr Res 38:275-289

96. Nonat A, Lecoq X (1996) The stucture, stoichiometry and properties of C-S-H prepared by C3S hydration under controlled solution. In: Colombet P, Grimmer AR, Zanni H, Sozzani P (eds) Nuclear magnetic resonance spectroscopy of cement based materials. Springer, Berling, pp 197-207

97. Boualleg S, Bencheikh M, Belagraa L, Daoudi A, Chikouche MA (2017) The combined effect of the initial cure and the type of cement on the natural carbonation, the portlandite content, and nonevaporable water in blended cement. Adv Mater Sci Eng 2017:1-17

98. Jennings HM (2000) A model for the microstructure of calcium silicate hydrate in cement paste. Cem Concr Res 30:101-116

99. Kapeluszna E, Kotwica L, Rozycka A, Golek L (2017) Incorporation of Al in C-A-S-H gels with various Ca/Si and Al/ Si ratio: Microstructural and structural characteristics with DTA/TG, XRD, FTIR and TEM analysis. Constr Build Mater 155:643-653

100. Thomas JJ, Jennings HM (2006) A colloidal interpretation of chemical aging of the C-S-H gel and its effects on the properties of cement paste. Cem Concr Res 36:30-38

101. Hinsinger P, Jailard B (1993) Root-induced release of interlayer potassium and vermiculitisation of phlogopite as related to potassium depletion in the rhizosphere of ryegrass. J Soil Sci 44:525-534

102. Sparks DL, Martens DC, Zelanzy LW (1980) Plant uptake and leaching of applied indigenous potassium in Dothan soils. Agron J 72:551-555

103. Velde B, Peck TR (2002) Clay mineral changes in the morrow experimental plots university of Illinois. Clays Clay Miner 50:364-370

104. Nelson JD, Miller DJ (1992) Expansive soil: problems and practice in foundation and pavement engineering. Wiley, New York

105. Emeh C, lgwe O (2016) The combined effect of wood ash and lime on the engineering properties of expansive soils. Int J Geotech Eng 10(3):246-256

106. Petry TM, Armstrong JC (1989) Stabilisation of expansive soils. Transp Res Rec 1219:103-112

\section{Publisher's Note}

Springer Nature remains neutral with regard to jurisdictional claims in published maps and institutional affliations. 